\title{
Immunoassay for Monitoring Pesticide Contamination in Agricultural Products
}

\author{
Eun-Kee Park · Hu Jang Lee** \\ Research and Education Unit, Dust Diseases Board, Sydney, NSW, Australia \\ *Research Institute of Life Sciences, College of Veterinary Medicine, Gyeongsang National University, Chinju, Korea \\ (Received November 3, 2008/Revised November 17, 2008/Accepted December 8, 2008)
}

\begin{abstract}
Much of the increase in agricultural productivity over the past half century has been due to the control of the pests with synthetic pesticides. The use of these pesticides has caused environmental problems and public health concern. The guidelines of maximum residue levels of pesticides in agricultural products has been well documented but more careful monitoring of their residues is required. Pyrethorid class pesticides are dominant in modern agricultural industry but public health concerns have been recently considered. The major route of pesticide exposure is the diet and with improved surveillance of pyrethorid residues in agricultural products their exposure should be controlled and minimized. In suitable products with reduced matrix effects such as agricultural products, aqueous samples, fruits and vegetables the use of immunoassays for pyrethorid residue monitoring could satisfy this requirement. Immunoassays have several advantages, namely they are highly sensitive, selective and cost-effective and enable large-scale sample handling and analysis in the laboratory.
\end{abstract}

Keywords: immunoassay, monitoring, pesticides, pyrethroids, agricultural products

\section{Introduction}

It is well documented that pesticide exposure has caused acute and/or chronic adverse health effects. ${ }^{1-3)}$ Concerns about pesticide exposure in children have increased due to their small body mass and rapid development of internal organs. ${ }^{46}$ )

A major route of exposure to pesticides and other environmental contaminants is through diet. ${ }^{7-10)}$ According to The National Research Council report entitled as 'Pesticides in the Diets of Infants and Children', ${ }^{11)}$ dietary intake is the major source of pesticide exposure to infants and children. Children have higher uptakes of organophosphates and pyrethroids with diet than adults. ${ }^{12)}$ To reduce and/or avoid dietary pesticide exposures, the levels of pesticide exposure based upon daily intake of a given chemical should be maintained below

Corresponding author: Research Institute of Life Sciences, College of Veterinary Medicine, Gyeongsang National University

Tel: 82-55-751-6642, Fax: 82-55-751-5803

E-mail: hujang@gnu.ac.kr maximum residue levels (MRLs). It is an essential step to monitor or screen pesticide residues in agricultural products prior to reaching to consumer's table. There are several reasons for increased demand for imported foods. A variety of staples and more high-values food items have been traded to satisfy consumers' demand, and the global market size has been growing around the world. If proper monitoring systems of pesticide residues in agricultural products have not been adopted, a potential exposure to pesticides may be increased followed by adverse health outcomes to be expected. In this article, we endeavor to describe the application of immunoassay monitoring to detect pesticide residues in agricultural products, in particular pyrethroid class pesticides, which are widely used in modern agriculture.

\section{Pesticides and Agriculture}

Much of the increase in agricultural productivity over the past half century has been due to pest control with synthetic pesticides. Estimates of the 
pest problem on a world scale suggest that without insect pests, world food production would be increased by about a third. ${ }^{13)}$ In the 1940s and 1950s organochlorine compounds were the dominant insecticides. The insecticidal activity of dichlorodiphenyltrichloroethane (DDT) was discovered in 1939 and it was manufactured from 1943 onward-becoming the most widely used insecticide in the world. ${ }^{14)}$ From about 1945 several other organochlorine insecticides such as aldrin, dieldrin, heptachlor and endrin were introduced. Organophosphorus insecticides were introduced initially in the late 1940s and were increasingly preferred to the organochlorines during the 1960s. Carbamate insecticides were also introduced at this time. As pyrethroids are extremely toxic to insects but are low toxic to mammals, they were used from the early 1970s. They are widely used in modern agriculture. There has been an increase in the use of herbicides in large-scale agricultural production because of labor and fuel costs to control weeds, and an emphasis on reduced tillage for soil conservation. Herbicides now account for $85 \%$ of all agrochemical use in the USA and $45 \%$ of world agrochemical use. ${ }^{15)}$ In the 1950 s a wide variety of broad-spectrum herbicides was introduced including the phenoxyacetic acids, carbamates and bipyridylium herbicides. Later, in the 1960s, compounds such as substituted phenylureas and triazines became available. The release of new compounds for testing in the field has now reached several hundred per year, and among these a number of herbicides with high potency and selectivity have been found. ${ }^{16)}$

The extensive use of crop protection chemicals can result in a range of problems including the development of resistance in pests, environmental damage, and public health concerns such as cancercausing potential or toxic effects. Pesticides have been also used on animal farms to control insects. Therefore, there is widespread concern about the presence of pesticide residues in foods and the environment. Some pesticides are extremely resistant to degradation resulting in residues in wildlife and natural ecosystems. Rural and urban residents could be exposed to agricultural pesticides either directly during crop applications or indirectly in air, foods, plants, soils or water. ${ }^{17)}$

\section{Pyrethroid Class Pesticides}

Synthetic pyrethroid class pesticides are the most frequently used insecticides in modern agriculture, forestry, horticulture, domestic, public health and veterinary applications due to their general high bioefficacy and low toxicity to birds and mammals. ${ }^{18,19)}$ In humans, pyrethroids are hydrolyzed by hepatic microsomal enzyme, which eliminates the pesticide and its metabolites almost completely from the body in 2 to 4 days. ${ }^{20)}$

Cyfluthrin, cypermethrin, esfenvalerate, lambdacyhalothrin and permethrin are most popular pyrethroids in the world market. Among these permethrin is the most common pyrethroid used as the active ingredient in personal care products, such as shampoos and lotions for lice. Permethrin consisted of cis- and trans- configuration. The cisisomer is more toxic than the trans-isomer which is the more abundant isomer $(60-75 \%)$ in the commercial products. ${ }^{21,22)}$ The lethal dose (LD) of permethrin is variable because of different proportions of the isomers in test materials. The acute oral $\mathrm{LD}_{50}$ value for permethrin in mice is $540-2690 \mathrm{mg}$ $\mathrm{kg}^{-1}$. ${ }^{23)}$ Permethrin appears to be highly toxic to fish and bees. ${ }^{23)}$

Pyrethroids have been detected as surface water contaminants which impact adversely on an aquatic ecosystems. ${ }^{24)}$ According to toxicological studies, non-target invertebrates and aquatic organisms are extremely sensitive to the neurotoxic effects of these insecticides. ${ }^{25-27)}$ The studies investigating the effects of the pyrethroids on human health showed that adverse effects include suppression of immune system after exposure, ${ }^{28)}$ lymph node and splenic damage and carcinogenesis ${ }^{29)}$ and endocrine disruption. ${ }^{30}$ ) Recent reports of chronic illness have linked with low-level exposure to synthetic pyrethroid insecticides. ${ }^{31)}$ Pyrethroid residues in foods and drinking water are a public health concern because a major route of exposure to pesticides is through the diet. ${ }^{8,32,33)}$ Current analytical methods for the detection of pyrethroids involve a multistep sample cleanup procedure followed by gas chromatography (GC) or high-performance liquid chromatography-mass spectrometry (HPLCMS). ${ }^{33-36}$ These methods work well but are relatively time-consuming, expensive, require skilled operators, 
and are not particularly suitable for large numbers of samples. In addition, the amount of chemicals and toxic solvents used are of environmental concern.

\section{Immunoassays to Monitor Pesticides in Agricultural Products}

Several simple methods have been developed to detect pesticide residues in agricultural products. Of these, an immunoassay provides a sensitive, selective, and rapid method for the detection of these pesticides at trace levels in agricultural products. ${ }^{37-39,41)}$ Immunoassay has the ability to handle large numbers of samples simultaneously, sample workup is relatively simple, and there are cost benefits secured from less sample preparation and higher throughput. Commonly, pesticides could be extracted from any dietary items with organic solvents which may tolerate the antibodies' action in the immunoassay which decreased the sensitivity of the immunoassay. In order to use the immunoassay for pesticide screening in agricultural products, the matrix effects caused by the interferences should be considered and removed prior to a use of immunoassay. A simple dilution of the extracts or samples should minimize matrix effects without a further cleanup or concentration step. ${ }^{38,40-42)}$ This method, however, sometimes decreases the assay

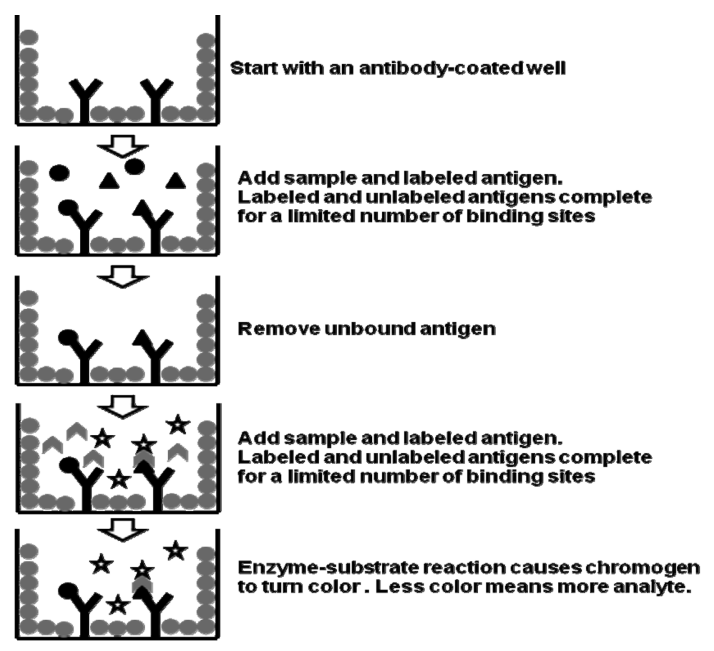

Fig. 1. ELISA procedure for detection of pyrethroid residues. $\mathbf{Y}$, antibody; $\mathbf{O}$, analyte; $\boldsymbol{\Delta}$, labeled antigen; $\wedge$, substrate; chromogen. sensitivity and increases the limit of detection by not adequately removing unwanted materials. To compensate the disadvantage of a simple dilution method, some assays have employed extraction and cleanup of pesticides using Solid Phase Extraction (SPE), liquid-liquid extraction (LLE) or supercritical fluid extraction. Fig. 1 is represented ELISA procedure for detection of pyrethroid residues.

\section{Application of Immunoassay for Measuring Pyrethroid Residues}

Several studies applied immunoassays to the quantitative detection of pyrethriod residues in some agricultural products. An enzyme-linked immunosorbent assay (ELISA) was used to detect deltamethrin in milk. ${ }^{38)}$ The LLE method was used to determine deltamethrin in regular fat milk in this study where a lower detection limit was 2.2 $\mu \mathrm{g} \mathrm{L}^{-1}$. The ELISA method is capable of screening milk samples for deltamethrin. Park et al. ${ }^{39)}$ showed the ELISA was useful to screen for cypermethrin and permethrin in wines with a simple and direct dilution. A matrix effect in the ELISA assay was minimized in diluted wines with phosphate-buffered saline containing $40 \%$ methanol. The cypermethrin concentrations that reduced absorbance to $50 \%$ of the maximum concentration $\left(\mathrm{IC}_{50}\right)$ were $46.4 \mu \mathrm{g} \mathrm{L} \mathrm{L}^{-1}$ in 200 -fold diluted red wine and $36.8 \mu \mathrm{g} \mathrm{L}^{-1}$ in 10-fold diluted white wine. The $\mathrm{IC}_{50}$ values of permethrin in 200-fold diluted red and white wines were 2.9 and $2.6 \mu \mathrm{g}$ $\mathrm{L}^{-1}$, respectively. In these samples, the limit of quantification (LOQ) for cypermethrin and permethrin analyzed by ELISA in wines were as low as $50 \mu \mathrm{g}$ $\mathrm{L}^{-1}$. Nakata et $a l^{43)}$ demonstrated the ELISA has been used to determine flucythrinate in tea extract without a further clean-up procedure. The LOQ for flucythrinate in tea extract was as low as 0.3 $\mathrm{mg} \mathrm{L}^{-1}$. The ELISA detected flucythrinate spiked in tea extracts of samples with the mean recovery of $>100 \%$.

Several ELISA studies showed pyrethroids could be measured in fruits, grains and vegetables. Lee et $a l^{44)}$ measured deltamethrin in whole grain using the LLE method (methanol extraction) followed by a simple dilution without a further 
cleanup. The ELISA provided $0.013 \mathrm{mg} \mathrm{kg}^{-1}$ of the LOQ with a good recovery of $>90 \%$ from grain extracts. Nakata et al. ${ }^{43}$ determined flucythrinate from apple. The apple methanol extract was diluted with distilled water which was then directly used for the ELISA assay. The LOQ for flucythrinate in apple extract was as low as $0.3 \mathrm{mg} \mathrm{L}^{-1}$. The mean recovery of flucythrinate spiked in apple was $>96 \%$ in this study. Park et al. ${ }^{39)}$ used a simple and direct dilution of the extracts from apple, banana, cucumber, lettuce, onion, and peach to determine permethrin using a competitive indirect ELISA method. The $\mathrm{IC}_{50}$ values of permethrin in 200-fold diluted the extracts of fruits and vegetables were less than $2.7 \mu \mathrm{g} \mathrm{L}^{-1}$. The LOQs of permethrin in fruits and vegetables excepted for cucumber were as low as $70 \mu \mathrm{g} \mathrm{kg}^{-1}$. The average of permethrin recoveries from fruit and vegetable samples were more than $70 \%$. In order to improve selectitivity of target compounds, Kaware et al. ${ }^{45)}$ developed sol-gel immunoaffinity purification (solgel IAP) method to minimize interferences from food samples for determining bioallethrin. The ELISA method found the sol-gel IAP reduced significantly the background interferences of vegetable samples such as tomato, cucumber and strawberry after acetone extraction. The recovery of spiked bioallethrin from strawberry with this reached $100 \%$. This study showed IAP method should enhance application of the ELISA monitoring method.

\section{Conclusions}

Pesticide use has a vital role in reducing damage to crops and livestock by pests, and improving productivity in the agricultural industry. It is clear that worldwide food production would be decreased without a proper control of pests.

The diet is the major source of the contaminants that should be monitored and screened for public health concerns, especially in children. Screening methods requiring rapid results from a large number of samples are essential to conduct this task. The immunoassay method, although a qualitative, semi-quantitative and limited multi-residue detection method, may provide a solution. Immunoassay methods have the potential to be routinely employed for monitoring of these chemicals as they are rapid, selective and have high throughput capabilities. The development and application of immunoassay techniques to detect pyrethroids in some suitable agricultural products may be more effective in reducing pesticide exposures and in the prevention of adverse health effects.

\section{References}

1. Reigart, J.R. and Roberts, J.R. : Recognition and management of pesticide poisonings, 5th ed. Reigart JR and Roberts JR, U.S. Environmental Protection Agency, Washington, D.C., 2-6, 1999.

2. Carpenter, D.D., Arcaro, K. and Spink, D.C. : Understanding the human health effects of chemical mixtures. Environ Health Perspect, 110, 25-42, 2002.

3. Bassil, K.L., Vakil, C., Sanborn, M., Cole, D.C., Kaur, J.S. and Kerr, K.J. : Cancer health effects of pesticides: systematic review. Canadian Family Physician, 53, 1704-1711, 2007.

4. Faustman, E.M., Sibernagel, S.M., Fenske, R.A., Burbacher, T.M. and Ponce, R.A. : Mechanisms underlying children's susceptibility to environmental toxicants. Environmental Health Perspectives, 108, 13-21, 2000

5. Handal, A.J., Lozoff, B., Breilh, J. and Harlow, S.D. : Neurobehavioral development in children with potential exposure to pesticides. Epidemiology, 18, 312-320, 2007.

6. Tulve, N.S., Egeghy, P.P., Fortmann, R.C., Whitaker, D.A., Nishioka, M.G., Naeher, L.P. and Hilliard, A. : Multimedia measurements and activity patterns in an observational pilot study of nine young children. Journal of Exposure Science \& Environmental Epidemiology, 18, 31-44, 2008.

7. Dougherty, C.P., Henricks, H.S., Reinert, J.C., Panyacosit, L., Axelrad, D.A. and Woodruff, T. : Dietary exposures to food contaminants across the United States. Environmental Research, 84, 170$185,2000$.

8. Andrew, C.C., Pellizzari, E.D., Whitmore, R.W., Quackenboss, J.J., Adgate, J. and Sefton, K. : Distributions, associations, and partial aggregate exposure of pesticides and polynuclear aromatic hydrocarbons in the Minnesota Children's Pesticide Exposure Study (MNCPES). Journal of Exposure Analysis and Environmental Epidemiology, 13, 100-111, 2003.

9. Muntean, N., Jermini, M., Small, I., Falzon, D., Furst, P., Migliorati, G., Scortichini, G., Forti, A.F., Anklam, E., von Holst, C., Niyazmatov, B., Bahkridinov, S., Aertgeerts, R., Bertollini, R., Tirado, C. and Kolb, A. : Assessment of dietary exposure to some persistent organic pollutants in the Republic 
of Karakalpakstan of Uzbekistan. Environmental Health Perspectives, 111, 1306-1311, 2003.

10. Schecter, A., Quynh, H.T., Pavuk, M., Papke, O., Malisch, R. and Constable, J.D. : Food as a source of dioxin exposure in the residents of Bien Hoa City, Vietnam. Journal of Occupational and Environmental Medicine, 45, 781-788, 2003.

11. National Research Council : Pesticides in the diets of infants and children. National Academy Press, Washington, D.C., 1993.

12. Becker, K., Seiwert, M., Angerer, J., KolossaGehring, M., Hoppe, H.W., Ball, M., Schulz, C., Thumulla, J. and Seifert, B. : GerES IV Pilot Study: assessment of the exposure of German children to organophosphorous and pyrethroid pesticides. International Journal of Hygiene and Environmental Health, 209, 221-233, 2006.

13. Van Emden, H.P. : Pest Control, 2nd Ed. Edward Arnold Publication, London and New York, 1989.

14. Cremlyn, R.J.W. : Pesticides: Preparation and Mode of Action. John Wiley and Sons. Ltd., New York, 1978.

15. Edwards, C.A. : Long-term ecological effects of herbicide: Field studies. Brighton Crop Protection Conference-Weeds-Proceeding, 2, 883-890, 1991.

16. Kulshrestha, G. and Singh, S.B. : Effect of herbicides on soil environment, in soil environment and Pesticides, ed. Prasad, D., Venus Publishing House, New Delhi. 293-313, 1994.

17. Kang, T.S. and Paik, N.W. : Exposure assessment of Korean orchard farmers to chlorpyrifos under consideration of exposure routes and sources. Korean Journal of Environmental Health Society, 25, 5968, 1999.

18. Leahey, J.P. : Metabolism and environmental degradation, in the pyrethroid insecticides, ed. Leahey, J.P., Taylor and Francis, London, 263-341, 1985.

19. Miadokova, E., Vickova, V., Trebaticka, M., Garajova, L., Grolmus, J., Podstavkova, S. and Vieck, D. : Effects of supercypermethrin, a synthetic development pyrethroid on four biological test systems. Mutation Research, 280, 161-168, 1992.

20. Burkhart, C.G. and Burkhart, C.N. : Topical pyrethroids: assessment of function and efficacy in head lice. International Pediatrics, 17, 209-212, 2002.

21. Angerer, J. and Ritter, A. : Determination of metabolites of pyrethroids in human urine using solidphase extraction and gas chromatography-mass spectrometry. Journal of Chromatography B, 695, 217-226, 1997.

22. Heudorf, U. and Angerer, J. : Metabolites of pyrethroid insecticides in urine specimens: current exposure in an urban population in Germany. Environmental Health Perspectives, 109, 213-217, 2001.

23. Tomlin, C.D.S. : The pesticide manual, 11th ed. Tomlin, C.D.S., British Crop Protection Council, Bracknell, 1997.
24. Moore, A. and Waring, C.P. : The effects of a synthetic pyrethroid pesticide on some aspects of reproduction in Atlantic salmon (Salmo salar L.). Aquatic Toxicology, 52, 1-12, 2001.

25. Coates, J.R., Symonik, D.M., Branbury, S.P., Dyer, S.D., Timson, L.K. and Atchison, G.J. : Toxicology of synthetic pyrethroids in aquatic organisms: An overview. Environmental Toxicology and Chemistry, 8, 671-679, 1989.

26. Haya, K. : Toxicity of pyrethroid insecticides to fish. Environmental Toxicology and Chemistry, 8, 381-391, 1989.

27. Schimmel, S.C., Garnas, R.L., Patrick, J.M. Jr. and Moore, J.C. : Acute toxicity, bioconcentration, and persistence of AC 222-705, benthiocarb, chlorpyrifos, fenvalerate, methyl parathion, and permethrin in the estuarine environment. Journal of Agricultural and Food Chemistry, 31, 104-113, 1983.

28. Repetto, R.C. : Pesticides and the immune system in the public health risks, ed. Repetto, R.C. and Baligia, S.S., World Resources Institute, National Center for Food and Agricultural Policy, Washington, D.C., 1996.

29. Hallenbeck, W.H. and Cunningham-Burns, K.M. : Pesticides and Human Health. Springer-Verlag, New York, 118-119, 1985.

30. Go, V., Garey, J., Wolff, M.S. and Pogo, B.G.T. : Estrogenic potential of certain pyrethroids compounds in the MCF-7 human breast carcinoma cell line. Environmental Health Perspectives, 107, 173177, 1999

31. Kolaczinski, J.H. and Curtis, C.F. : Chronic illness as a result of low-level exposure to synthetic pyrethroid insecticides: a review of the debate. Food and Chemical Toxicology, 42, 697-706, 2004.

32. Dougherty, C.P., Henricks, H.S., Reinert, J.C., Panyacosit, L., Axelrad, D.A. and Woodruff, T. : Dietary exposure to food contaminants across the United States. Environmental Research, 84, 170185,2000

33. Mattern, G.C., Liu, C.H., Louis, J.B. and Rosen, J.D. : GC/MS and LC/MS determination of 20 pesticides for which dietary oncogenic risk has been estimated. Journal of Agricultural Food and Chemistry, 39, 700-704, 1991.

34. Martinez, G.M., Martinez, V.J.L., Garrido, F.A. and Gil, G.M.D. : Determination of cypermethrin, fenvalerate and cis- and trans-permethrin in soil and groundwater by high performance liquid chromatography using partial least-squares regression. Journal of Chromatography A, 727, 39-46, 1996.

35. Aguera, A., Contreras, M., Crespo, J. and Fernandez-Alba, A.R. : Multiresidue method for the analysis of multiclass pesticides in agricultural products by gas chromatography-tandem mass spectrometry. Analyst, 127, 347-354, 2002.

36. Avramides, E.J. and Gkatsos, S.A. : Multiresidue method for the determination of insecticides and tri- 
azine herbicides in fresh and processed olives. Journal of Agricultural Food and Chemistry, 55, 561-565, 2007.

37. Nunes, G.S., Marco, M.P., Ribeiro, M.L. and Barcelo, D. : Validation of an immunoassay method for the determination of traces of carbaryl in vegetable and fruit extracts by liquid chromatography with photodiode array and mass spectrometric detection. Journal of Chromatography A, 823, 109-120, 1998.

38. Lee, H.J., Watanabe, T., Gee, S.J. and Hammock, B.D. : Application of an enzyme-linked immunosorbent assay (ELISA) to determine deltamethrin residues in milk. Bulletin of Environmental Contamination and Toxicology, 71, 14-20, 2003.

39. Park, E.-K., Kim, J.H., Gee, S.J., Watanabe, W., Ahn, K.C. and Hammock, B.D. : Determination of pyrethroid residues in agricultural products by an enzyme-linked immunosorbent assay. Journal of Agricultural Food and Chemistry, 52, 5572-5576, 2004.

40. Wang, S., Zhang, J., Yang, Z., Wang, J. and Zhang, Y. : Development of two enzyme-linked immunosorbent assays for detection of endosulfan residues in agricultural products. Journal of Agricultural Food and Chemistry, 53, 7377-7384, 2005.

41. Moreno, M.-J., Plana, E., Montoya, A., Caputo, P. and Manclus, J.J. : Application of a monoclonalbased immunoassay for the determination of imazalil in fruit juices. Food Additives and Contaminants, 24, 704-712, 2007.

42. Rosso, I., Giraudi, G., Gamberini, R., Baggiani, C. and Vanni, A. : Application of an ELISA to the determination of benalaxyl in red wines. Journal of Agricultural Food and Chemistry, 48, 33-36, 2000.

43. Nakata, M., Fukushima, A. and Ohkawa, H. : A monoclonal antibody-based ELISA for the analysis of the insecticide flucythrinate in environmental and crop samples. Pest Management Science, 57, 269-277, 2001.

44. Lee, N., Beasley, H.L. and Skerritt, J.H. : Development of immunoassays for type II synthetic pyrethroids. 2. Assay specificity and application to water, soil, and grain. Journal of Agricultural Food and Chemistry, 46, 535-546, 1998.

45. Kaware, M., Bronshtein, A., Safi, A., Van Emon, J.M., Chuang, J.C., Hock, B., Kramer, K. and Altstein, M. : Enzyme-linked immunosorbent assay (ELISA) and sol-gel-based immunoaffinity purification (IAP) of the pyrethroid bioallethrin in food and environmental samples. Journal of Agricultural Food and Chemistry, 54, 6482-6492, 2006. 